\title{
Corrigendum
}

\section{Corrigendum to "All-ceramic or metal-ceramic tooth- supported fixed dental prostheses (FDPs)? A systematic review of the survival and complication rates. Part I: Single crowns (SCs)"

\author{
Irena Sailer ${ }^{a, *}$, Nikolay Alexandrovich Makarov ${ }^{a}$, Daniel Stefan Thoma ${ }^{b}$, \\ Marcel Zwahlen ${ }^{c}$, Bjarni Elvar Pjetursson ${ }^{d}$ \\ ${ }^{a}$ Division for Fixed Prosthodontics and Biomaterials, Center of Dental Medicine, University of Geneva, Geneva, \\ Switzerland \\ b Department of Fixed and Removable Prosthodontics and Dental Material Science, University of Zurich, Switzerland \\ c Department of Social and Preventive Medicine, University of Berne, Berne, Switzerland \\ d Department of Reconstructive Dentistry, Faculty of Odontology, University of Iceland, Reykjavik, Iceland
}

The authors would like to inform the readers of a needed clarification in this article:

Analyzing the survival rate of different types of all-ceramic crowns in part I of the review the material was divided into the following groups; feldspathic/silica-based ceramics, leucit/lithium-disilicate reinforced glass ceramics, glass infiltrated alumina, densely sintered alumina and densely sintered zirconia.

Nine studies reporting on 1049 zirconia based crowns were included in the analysis on densely sintered zirconia crowns in part I of the review. From the nine studies Passia et al. [1] was a clear outlier with respect to the outcomes of the zirconia ceramic crowns. This results of this study were added to the "densely sintered zirconia group", however, it did not include densely sintered zirconia crowns but crowns made from $\mathrm{ZrSiO}_{4}$ which have a lower flexural strength than crowns made from densely sintered zirconia. When this outlier study is excluded from the analysis the annual failure rate of densely sintered zirconia crowns decreases from $1.84 \%$ to $1.28 \%$ and the estimated 5-year survival rates increases from 91.2\% (95\% C.I.: $82.8-95.6 \%$ ) to $93.8 \%$ (95\% C.I.: $90.3-96.1 \%$ ). Comparing this to the 5 -year survival rate of metal-ceramic crowns of a $95.7 \%$ (95\% C.I.: $94.1-96.9 \%$ ) the difference decreases to $1.9 \%$. This difference does not reach statistical significance $(p=0.174)$. When the Passia et al. [1] was included in the analysis the difference was $4.5 \%$ and the $p$-value was 0.055 (as given in Table 4 of our publication)

As this study does not fit in any other group the options would have been be to exclude this study from the analysis like previously presented, change the definition of the zirconia group to "zirconia based ceramics" or to place Passia et al. [1] in a group of its own with a 5 -year survival rate of $74.8 \%$.

Our publication had a second slight error. Cehreli et al. [2] included two types of ceramic crowns in a randomized

* Corresponding author at: Division of Fixed Prosthodontics and Biomaterials, Center of Dental Medicine, University of Geneva, 19, RueBarthelemy-Menn, CH 1205 Geneva, Switzerland. Tel.: +41 223794050.

E-mail address: Irena.sailer@unige.ch (I. Sailer). 
controlled clinical trial. The included patients received 50 feldspathic ceramic crowns and 51 glass infiltrated alumina crowns. In Table 3 of our publication the 50 feldspathic ceramic crowns were incorrectly included under glass infiltrated alumina crowns. However, in the meta-analysis we performed those crowns were correctly included in two different material groups, and the results presented in our study remain unchanged by this error in Table 3 .

The authors wish to apologize for any inconvenience caused.

\section{R E F E R E N C E S}

[1] Passia N, Stampf S, Strub JR. Five-year results of a prospective randomised controlled clinical trial of posterior computer-aided design-computer-aided manufacturing $\mathrm{ZrSiO}_{4}$-ceramic crowns. J Oral Rehabil 2013;40:609-17.

[2] Cehreli MC, Kokat AM, Ozpay C, Karasoy D, Akca K. A randomized controlled clinical trial of feldspathic versus glass-infiltrated alumina all-ceramic crowns: a 3-year follow-up. Int J Prosthodont 2011;24:77-84. 